\title{
Reply to Letter to the Editor re: Tumour thickness in oral cancer using an intraoral ultrasound probe
}

\author{
Wouter L. Lodder
}

Received: 20 October 2010 / Accepted: 13 November 2010 / Published online: 12 December 2010

(C) The Author(s) 2010. This article is published with open access at Springerlink.com

\section{Dear Editor,}

We appreciate the comments made by the authors with regards to our paper "Tumour thickness in oral cancer using an intraoral ultrasound probe". It emerges that intra-oral ultrasound is helpful in decision making regarding management of the primary tumour and neck. We do agree with the authors that tumour thickness is not the only important predictive factor for lymph node metastasis, as we describe in the introduction section of our article, "other important characteristics of the tumour are: epidemiologic parameters such as age, sex, race, alcohol, and/or tobacco intake, clinical parameters (TNM stage, site) and histopathological parameters such as the tumour border, being either infiltrative or more pushing, perineural invasion and vascular invasion" [1].

In the opinion of the authors all parameters for lymph node metastasis should be studied together. In 2002 Yuen et al. [2] studied the prognostic significance of multiple factors for subclinical nodal metastasis in 72 patients with multivariate analysis. In the multivariate analysis, tumour thickness was the only significant independent prognostic factor for subclinical nodal metastasis $(p=0.031)$. T stage, vascular invasion, lymphatic vessel invasion, perineural invasion and shape were not significant prognostic for nodal metastasis.

Most of the described factors are not routinely determined, or only significant in univariate analysis (for example: basaloid variants [3], sialoadenotropism/ductal invasion [4]) and therefore will be more difficult to use as prognosticator.

\footnotetext{
W. L. Lodder $(\square)$

Section of Head and Neck Surgery, The Netherlands Cancer Institute/Antoni van Leeuwenhoek Hospital,

Plesmanlaan 121,

1066 CX Amsterdam, The Netherlands

e-mail: w.lodder@nki.nl
}

In 2005 Woolgar [5] reviewed histopathological prognosticators in oral and oropharyngeal squamous cell carcinoma. The influence of sialoadenotropism (extension of dysplasia down the orifices of minor salivary glands) and ductal invasion on survival is uncertain but both features are associated with increased local recurrence and second primary tumours. This conclusion is formulated based on the study by Daley et al. [4]. In $2.14 \%(26 / 1216)$ salivary ductal invasion was present, based upon those 26 cases they concluded "routine measured depth of ductal invasion appears to have no significance with respect to prognosis".

Furthermore the authors state bone involvement is significant histopathological prognostic, however in our study we only included T1 or T2 squamous cell carcinomas of the tongue or floor of mouth. Hence bone involvement was not present in our population.

With this study we tried to present our results with respect to the feasibility of ultrasound measurements of intra-oral tumour thickness, for that reason we published this article in a radiologically orientated journal. No statement was made to evaluate the significance of tumour thickness on prognosis and survival rate.

Since June 2007 we have been using a new intra-operative transducer. In our current treatment protocol, in tumours of less than 5-mm thick, PDT treatment can be used as light penetration up to $1 \mathrm{~cm}$. With this first analysis we showed that ultrasound with our new probe gave a Pearson's correlation up to $R=0.93$. Our measurements were performed by only one radiologist to have a similar test result in every patient.

It requires large studies and independent validation to evaluate inter- and intraobserver variability and the identification of a cut-off value with adequate utility for clinical decision making.

To conclude, we agree with the authors tumour thickness is an important, but not the only, predictive marker for lymph 
node metastasis, as such, it can help in decision-making with regard to management of the primary tumour and neck. Our purpose of this study was to evaluate only the feasibility of intra-oral measurements with our new probe.

Open Access This article is distributed under the terms of the Creative Commons Attribution Noncommercial License which permits any noncommercial use, distribution, and reproduction in any medium, provided the original author(s) and source are credited.

\section{References}

1. Lodder WL, Teertstra HJ, Tan IB, Pameijer FA, Smeele LE, van Velthuysen MLF, van den Brekel MWM (2010) Tumour thickness in oral cancer using an intra-oral ultrasound probe. Eur Radiol. doi:10.1007/s00330-010-1891-7

2. Po Wing Yuen A, Lam KY, Lam LK, Ho CM, Wong A, Chow TL, Yuen WF, Wei WI (2002) Prognostic factors of clinically stage I and II oral tongue carcinoma - a comparative study of stage, thickness, shape, growth pattern, invasive front malignancy grading, martinez-gimeno score, and pathologic features. Head Neck 24:513-520

3. Witzenburg SM, Niehans GA, George E, Daly K, Adams GL (1998) Basaloid squamous carcinoma: a clinical comparison of two histologic types with poorly differentiated squamous cell carcinoma. Otolaryngol Head Neck Surg 119:471-475

4. Daly TD, Lovas JG, Peters E, Wysocki GP, McGaw TW (1996) Salivary gland duct involvement in oral epithelial dysplasia and squamous cell carcinoma. Oral Surg Oral Med Oral Pathol Oral Radiol Endod 81:186-192

5. Woolgar JA (2006) Histopathological prognosticators in oral and oropharyngeal squamous cell carcinoma. Oral Oncol 42:229-239 